\title{
A Telemonitoring Intervention for Cirrhotic Ascites Management Is Cost-Saving
}

\author{
Patricia P. Bloom ${ }^{1}$ (D) Martin Ventoso ${ }^{2}$ - Elliot Tapper ${ }^{1} \cdot$ Jasmine Ha $^{3} \cdot$ James M. Richter $^{2,3}$
}

Received: 17 November 2020 / Accepted: 23 January 2021 / Published online: 6 May 2021

(c) The Author(s), under exclusive licence to Springer Science+Business Media, LLC, part of Springer Nature 2021

\begin{abstract}
Background Patients with cirrhosis and ascites experience frequent hospital admissions, leading to poor quality of life and high healthcare costs. Monitoring weight is a component of ascites care and telemonitoring may improve outcomes and costs. Goals

We aimed to evaluate the cost and outcomes of current care compared to a telemonitoring system for ascites.

Study

We developed a decision-analytic model that examined 100 simulated patients over a 6-month horizon. We compared usual care to a new telemonitoring program, which we estimate costs $\$ 50,000 / 6$ months.

Results The cost of standard of care for 100 patients with cirrhotic ascites over a 6-month period is $\$ 167,500$ more expensive than telemonitoring. By varying parameter probabilities by $\pm 10 \%$ and outcome costs by $\pm 20 \%$, we found that standard of care remains more expensive than care with a telemonitoring intervention by $\$ 9400$ to $\$ 340,200$ per 6-month period. Standard of care leads to 9 more admissions (range 4 to 12) than a telemonitoring intervention, while telemonitoring leads to 9 more outpatient visits (range 6 to 9) and 28 additional outpatient large volume paracenteses (LVPs) (range 17 to 28). With more and less expensive telemonitoring interventions, standard of care remained more expensive. With $50 \%$ adherence to the intervention, standard of care was $\$ 89,848$ more expensive.

Conclusions In almost all probability and cost scenarios, a telemonitoring intervention is cost-saving for the management of cirrhotic ascites. Using hospital admissions as a surrogate for quality of care, patient outcomes are improved primarily though more proactive medical intervention and more LVPs.
\end{abstract}

Keywords Healthcare delivery $\cdot$ Ascites $\cdot$ Telemedicine $\cdot$ Cost-effectiveness $\cdot$ Technology

\section{Abbreviations}

LVP Large volume paracentesis

TIPS Transjugular intrahepatic portosystemic shunt

DRG Diagnosis-related group

CPT Current procedural terminology

An editorial commenting on this article is available at https://doi. org/10.1007/s10620-021-07020-3.

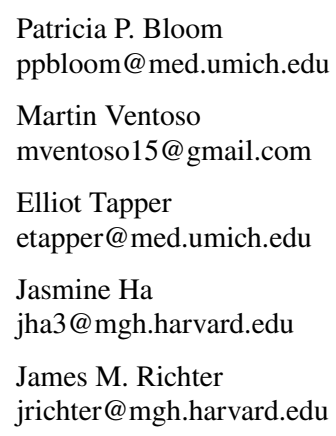

\section{Introduction}

Patients with cirrhosis experience a large number of hospital admissions and at a significant financial cost [1-3]. Ascites is the most common reason for hospitalization [1]. Nearly one-quarter of early hospital readmissions for cirrhosis are preventable. Two of the main reasons for readmission are

1 Gastrointestinal Unit, University of Michigan, Taubman Center, Floor 1, Reception G, 1500 E. Medical Center Dr., Ann Arbor, MI, USA

2 Department of Medicine, Harvard Medical School, Boston, USA

3 Gastrointestinal Unit, Massachusetts General Hospital, Boston, USA 
failure to either arrange outpatient paracentesis for symptomatic ascites or recognize warning signs of over-diuresis [4]. Data are limited, however, supporting interventions that can reduce the burden of hospitalization for patients with ascites [5-9].

Bodyweight is a useful proxy for ascites volume. Monitoring weight is therefore a component of society guidelines for ascites management and ascites treatment trials [10, 11]. Weight telemonitoring may address the two key failures of outpatient ascites management by identifying rapidly increasing or decreasing weight. Single-center studies have generated optimism for weight telemonitoring programs in patients with cirrhotic ascites, but such programs have been limited to narrow populations [7, 12].

In the present COVID-19 era, telemedicine is critical to providing access to timely and safe care. Before undertaking a new intervention with potential incremental costs, data are needed to determine the potential for benefits and global cost saving. We performed an analysis to evaluate the cost and outcomes of current care compared to care enhanced with a telemonitoring system for ascites in place.

\section{Materials and Methods}

\section{Study Design Overview}

We developed a decision-analytic model for patients with cirrhotic ascites. The model examined 100 simulated patients beginning with a patient's next encounter for ascites at a transplant referral center and progressed over a 6-month horizon. We compared usual care where patients are managed through a combination of routine visits and urgent presentations for care based on symptoms to a new telemonitoring program. The telemonitoring system tracks patients' weight remotely through Bluetooth-enabled scales and provides automated, early alerts to providers about weight changes (Fig. 1). An administrative staff member or medical assistant enrolls patients and provides technical support. The outcomes modelled included global costs as well as the number of hospital admissions, office visits, and paracenteses. All outcomes were evaluated from the payer perspective. This study did not use patient identifying data and therefore was exempt from institutional review board review.

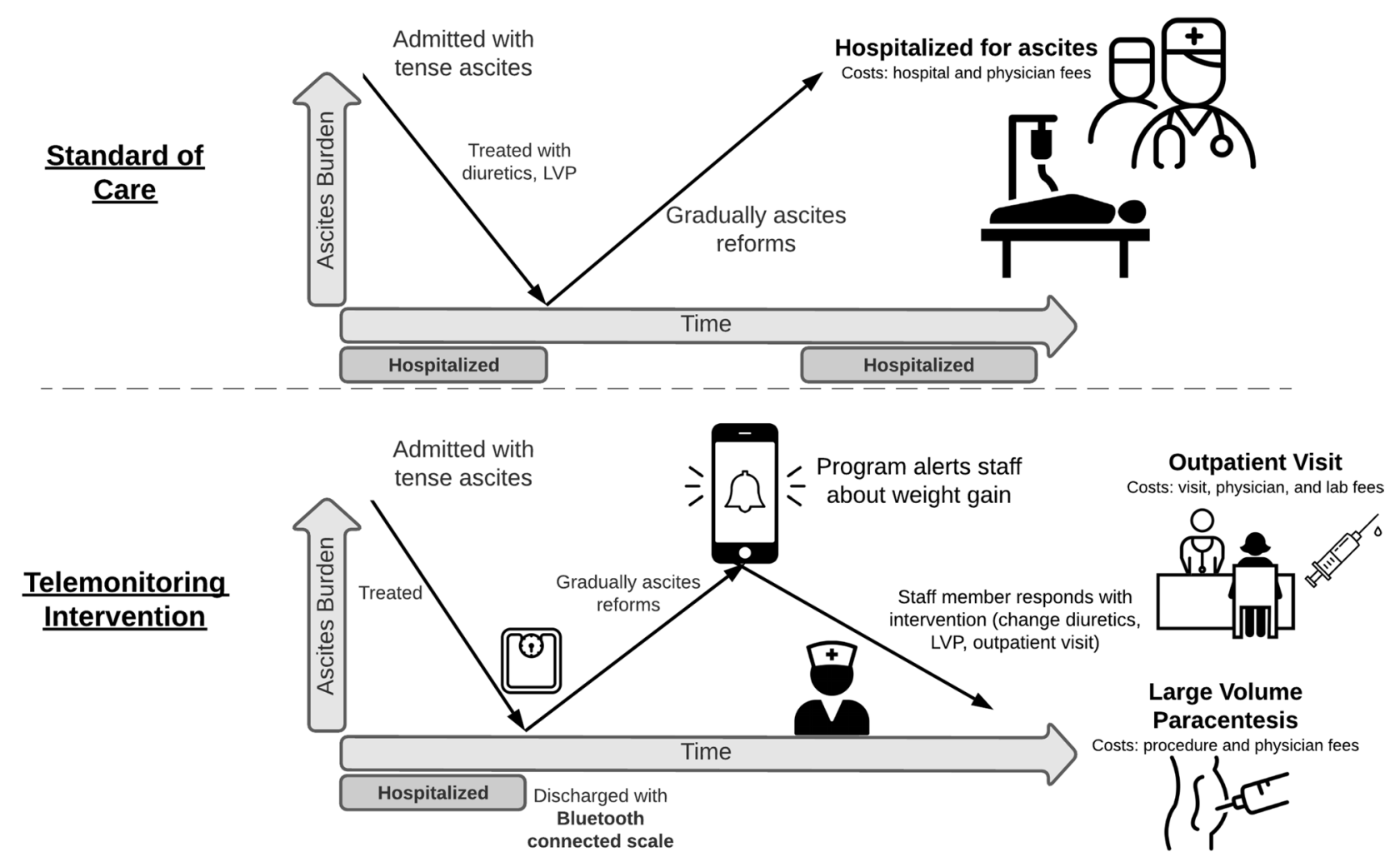

Fig. 1 Potential costs of ascites management 


\section{Model Development}

We used a combination of inputs centering on published local experience to develop a decision tree to model care processes and outcomes for patients with cirrhotic ascites (Fig. 2; Supplementary Fig. 1 for comprehensive model). Each patient began the simulation with a health-state stratified according to 4 key elements: location of the first encounter, volume of ascites, response to therapy, and treatment complications. All model inputs are presented in Table 1.

\section{Standard of Care Probabilities}

The probability that a patient's next encounter for cirrhotic ascites will be inpatient is $20 \%$ and outpatient is $80 \%$ [13]. Patients can present with mild, moderate, or large-volume ascites, which corresponds with the International Ascites Club grading system I-III [14]. Data from a two-center cohort suggest that the probability of inpatients having ascites that is mild $20 \%$, moderate $60 \%$, and large 20\% [15]. Response to low-salt diet and diuretic treatment of ascites can be categorized as partial, complete, or no response. In the same cohort as above, even in those who developed renal failure with ascites treatment, one-quarter had complete response and onequarter had partial response to ascites treatment [16]. Depending on the patient population, $10-30 \%$ of patients have no response to ascites diet and diuretic treatment $[9$, 14, 15]. Ascites treatment complications were defined as major if they required hospitalization. Recurrent ascites is the most common major complication of ascites treatment, with $23 \%$ of patients requiring re-admission for this complication within 90 days of a hospital discharge in a large nationwide cohort [3]. In patients without baseline renal failure, approximately $20 \%$ will experience adverse events on combined diuretic therapy, including electrolyte disturbance and renal injury [17]. Complications of large volume paracentesis (LVP) and transjugular intrahepatic portosystemic shunt (TIPS) are uncommon $[18,19]$.

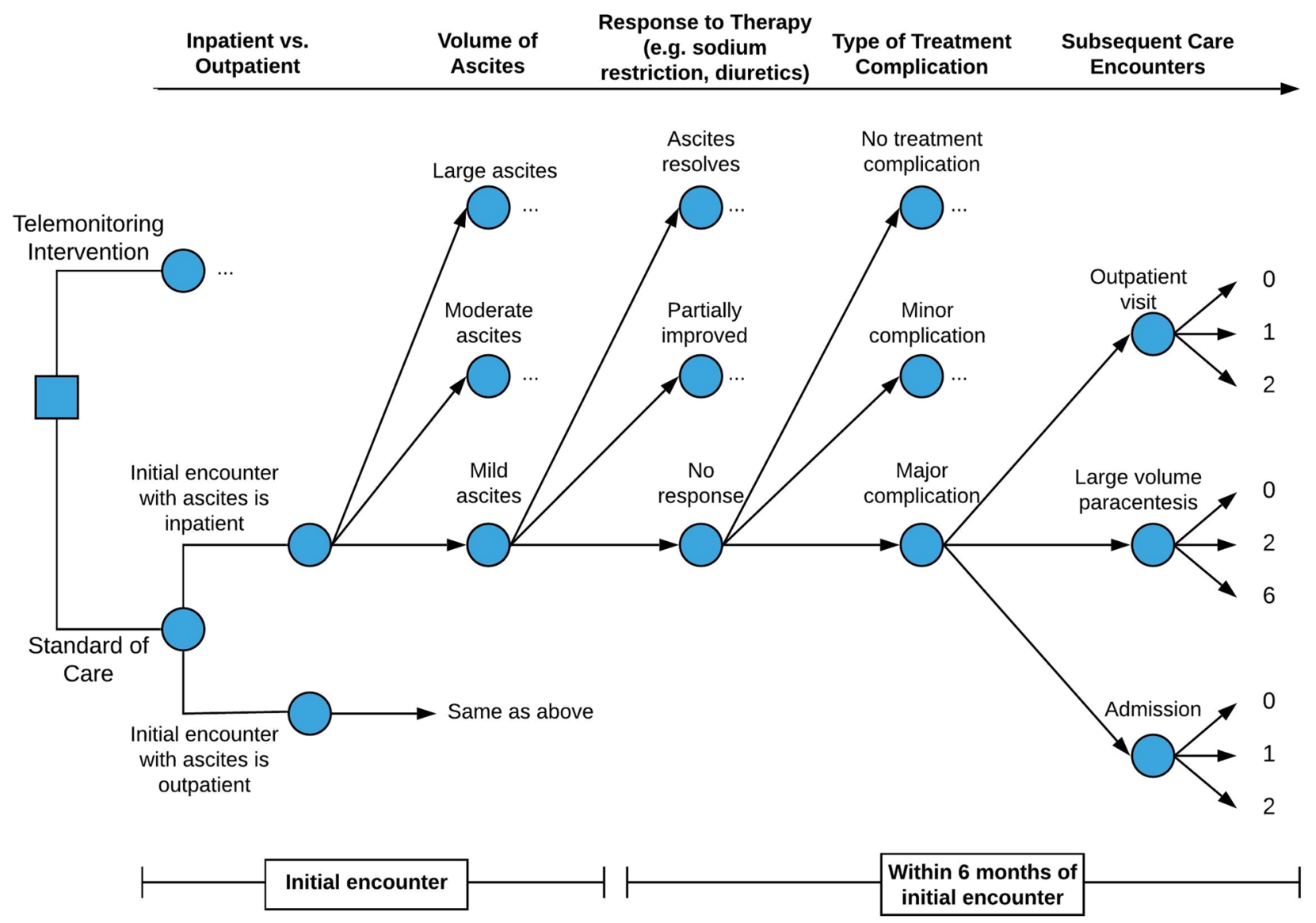

Fig. 2 Model of care outcomes for patients with cirrhotic ascites. A decision tree modeling the 4 key elements that influence outcomes: location of first encounter, volume of ascites, response to therapy, and treatment complications. Each “..." represents identical branch points from the node below. In other words, much like "mild ascites" can resolve, partially improve, or have no response to treatment, so can moderate and large ascites 
Table 1 Model parameters in standard of care

\begin{tabular}{|c|c|c|c|c|c|c|}
\hline Type of parameter & Parameter & & Probability $^{\mathrm{a}}$ & Source & Low $^{\mathrm{b}}$ & High $^{\mathrm{b}}$ \\
\hline \multirow[t]{2}{*}{ Location of first encounter } & Inpatient & & .20 & {$[13]$} & .10 & .30 \\
\hline & Outpatient & & .80 & & .90 & .70 \\
\hline \multirow[t]{6}{*}{ Volume of ascites } & \multirow[t]{3}{*}{ Inpatient } & Mild & .20 & {$[15]$} & .30 & .10 \\
\hline & & Moderate & .60 & & .60 & .60 \\
\hline & & Large & .20 & & .10 & .30 \\
\hline & \multirow[t]{3}{*}{ Outpatient } & Mild & .40 & & .50 & .30 \\
\hline & & Moderate & .50 & & .50 & .50 \\
\hline & & Large & .10 & & .00 & .20 \\
\hline \multirow[t]{9}{*}{ Response to therapy } & \multirow[t]{3}{*}{ Mild } & Ascites resolves & .90 & {$[9,14-16]$} & 1.00 & .80 \\
\hline & & Partially improves & .09 & & .00 & .09 \\
\hline & & No response & .01 & & .00 & .11 \\
\hline & \multirow[t]{3}{*}{ Moderate } & Ascites resolves & .50 & & .60 & .40 \\
\hline & & Partially improves & .42 & & .40 & .42 \\
\hline & & No response & .08 & & .00 & .18 \\
\hline & \multirow[t]{3}{*}{ Large } & Ascites resolves & .20 & & .30 & .10 \\
\hline & & Partially improves & 60 & & .60 & 60 \\
\hline & & No response & .20 & & .10 & .30 \\
\hline \multirow[t]{9}{*}{ Type of treatment complication } & \multirow[t]{3}{*}{ Ascites resolves } & No complication & .80 & {$[3,17-19]$} & .90 & .70 \\
\hline & & Minor complication & .15 & & .10 & .15 \\
\hline & & Major complication & .05 & & .00 & .15 \\
\hline & \multirow[t]{3}{*}{ Partially improves } & No complication & .40 & & .50 & .30 \\
\hline & & Minor complication & .30 & & .30 & .30 \\
\hline & & Major complication & .30 & & .20 & .40 \\
\hline & \multirow[t]{3}{*}{ No response } & No complication & .10 & & .20 & .00 \\
\hline & & Minor complication & .40 & & .40 & .40 \\
\hline & & Major complication & .50 & & .40 & 60 \\
\hline \multirow[t]{9}{*}{ Subsequent care encounters ${ }^{c}$} & \multirow[t]{3}{*}{ No complication } & $0,1,2$ visits & $.20, .60, .20$ & {$[1-5,11,13,20-23]$} & $.30, .60, .10$ & $.10, .60, .30$ \\
\hline & & $0,2,6$ LVPs & $.80, .15, .05$ & & $.90, .10, .00$ & $.70, .15, .15$ \\
\hline & & $0,1,2$ admits & $.90, .08, .02$ & & $1.00, .00, .00$ & $.80, .08, .12$ \\
\hline & \multirow[t]{3}{*}{ Minor complication } & $0,1,2$ visits & $.10, .50, .40$ & & $.20, .50, .30$ & $.00, .50, .50$ \\
\hline & & $0,2,6$ LVPs & $.60, .30, .10$ & & $.70, .30, .00$ & $.50, .30, .20$ \\
\hline & & $0,1,2$ admits & $.80, .15, .05$ & & $.90, .10, .00$ & $.70, .15, .15$ \\
\hline & \multirow[t]{3}{*}{ Major complication } & $0,1,2$ visits & $.10, .40, .50$ & & $.20, .40, .40$ & $.00, .40, .60$ \\
\hline & & $0,2,6$ LVPs & $.30, .40, .30$ & & $.40, .40, .20$ & $.20, .40, .40$ \\
\hline & & $0,1,2$ admits & $0, .50, .50$ & & $0, .60, .40$ & $0, .40, .60$ \\
\hline
\end{tabular}

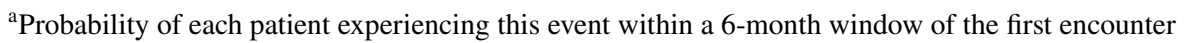

b "Low" sensitivity analysis is shifted $10 \%$ towards a less expensive outcome. "High" sensitivity analysis is shifted $10 \%$ towards a more expensive outcome

${ }^{\mathrm{c}} 3$ probabilities on each row

\section{Telemonitoring Intervention Probabilities}

Similar to the standard of care model, we used published data to develop a decision tree to model care and outcomes for patients with cirrhotic ascites enrolled in a telemonitoring intervention. All model inputs are presented in Table 2.

One study of 40 patients with enhanced case management and hepatology nursing support post-discharge increased outpatient attendance by $30 \%$ but did not reduce readmissions [6]. Another group studied 40 patients with cirrhotic ascites enrolled in an intensive multi-disciplinary outpatient monitoring program, complete with a day hospital and proactive titration of diuretics [9]. By comparison standard of care, 30-day readmission was reduced by nearly one-third (15.4\% vs. $42.4 \%)$. Another intensive outpatient monitoring program with a day hospital followed 80 patients with cirrhotic ascites and reduced early readmission by onethird (11.3\% vs. $29.5 \%)$ [5]. Finally, a 25-patient pilot study 
Table 2 Model parameters with telemonitoring intervention

\begin{tabular}{|c|c|c|c|c|c|c|}
\hline Type of parameter & Parameter & & Probability $^{\mathrm{a}}$ & Source & Low $^{\mathrm{b}}$ & High $^{\mathrm{b}}$ \\
\hline \multirow[t]{2}{*}{ Location of first encounter } & Inpatient & & .20 & {$[13]$} & .10 & .30 \\
\hline & Outpatient & & .80 & & .90 & .70 \\
\hline \multirow[t]{6}{*}{ Volume of ascites } & Inpatient & Mild & .20 & {$[15]$} & .30 & .10 \\
\hline & & Moderate & .60 & & .60 & .60 \\
\hline & & Large & .20 & & .10 & .30 \\
\hline & Outpatient & Mild & .40 & & .50 & .30 \\
\hline & & Moderate & .50 & & .50 & .50 \\
\hline & & Large & .10 & & .00 & .20 \\
\hline \multirow[t]{9}{*}{ Response to therapy } & Mild & Ascites resolves & .92 & {$[5-9]$} & 1.00 & .82 \\
\hline & & Partially improves & .07 & & .00 & .07 \\
\hline & & No response & .01 & & .00 & .11 \\
\hline & Moderate & Ascites resolves & .65 & & .75 & .55 \\
\hline & & Partially improves & .30 & & .35 & .30 \\
\hline & & No response & .05 & & .00 & .15 \\
\hline & Large & Ascites resolves & .35 & & .45 & .25 \\
\hline & & Partially improves & .50 & & .50 & .50 \\
\hline & & No response & .15 & & .05 & .25 \\
\hline \multirow[t]{9}{*}{ Type of treatment complication } & Ascites resolves & No complication & .82 & {$[5-9]$} & .92 & .72 \\
\hline & & Minor complication & .14 & & .08 & .14 \\
\hline & & Major complication & .04 & & .00 & .14 \\
\hline & Partially improves & No complication & .50 & & .60 & .40 \\
\hline & & Minor complication & .25 & & .25 & .25 \\
\hline & & Major complication & .25 & & .15 & .35 \\
\hline & No response & No complication & .20 & & .30 & .10 \\
\hline & & Minor complication & .35 & & .35 & .35 \\
\hline & & Major complication & .45 & & .35 & .55 \\
\hline \multirow[t]{9}{*}{ Subsequent care encounters } & No complication & $0,1,2$ visits & $.10, .70, .20$ & [5-9] & $.20, .70, .10$ & $.00, .70, .30$ \\
\hline & & $0,2,6$ LVPs & $.70, .20, .10$ & & $.80, .20, .00$ & $.60, .20, .20$ \\
\hline & & $0,1,2$ admits & $.90, .08, .02$ & & $1.00, .00, .00$ & $.80, .08, .12$ \\
\hline & Minor complication & $0,1,2$ visits & $.05, .45, .50$ & & $.15, .45, .40$ & $.00, .40, .60$ \\
\hline & & $0,2,6$ LVPs & $.50, .35, .15$ & & $.60, .35, .05$ & $.40, .35, .25$ \\
\hline & & $0,1,2$ admits & $.83, .13, .04$ & & $.93, .07, .00$ & $.73, .13, .14$ \\
\hline & Major complication & $0,1,2$ visits & $.05, .37, .58$ & & $.15, .37, .48$ & $.00, .32, .68$ \\
\hline & & $0,2,6$ LVPs & $.20, .45, .35$ & & $.30, .45, .25$ & $.10, .45, .45$ \\
\hline & & $0,1,2$ admits & $0, .58, .42$ & & $.10, .58, .32$ & $0, .48, .52$ \\
\hline
\end{tabular}

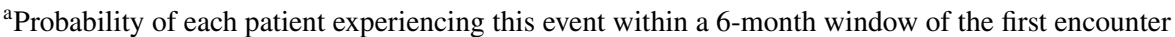

b "Low" sensitivity analysis is $10 \%$ lower than the predicted probability. "High" sensitivity analysis is $10 \%$ higher than the predicted probability

${ }^{c} 3$ probabilities on each row

of a remote weight monitoring program from our group found an $11 \%$ readmission rate for ascites, though a much higher rate for all-cause readmission [7]. We predict that a telemonitoring program specifically for patients undergoing ascites management, without day hospital or other ancillary supports, would likely fall somewhere between the outcomes of these four programs: increasing outpatient care utilization by approximately $15 \%$ and decreasing inpatient care utilization by approximately $15 \%$.

\section{Outcomes}

Outcomes included hospitalization, outpatient visits, and paracenteses. All outcomes were modelled as counts with respect to their contribution to global costs. Cost data were estimated in 2019 US dollars from Medicare reimbursements using diagnosis-related group (DRG) and fee schedule data based on Current Procedural Terminology (CPT) codes for 2019. We found that the average bundled cost of an 
outpatient visit is $\$ 202$ and for an inpatient stay is $\$ 26,006$ (Table 3).

In current practice, approximately three-quarters of patients have an outpatient follow visit within 6 months [13]. A large cohort of patients with a new diagnosis of cirrhotic ascites required an average 2.6 LVPs per patient per year [20]. Several large studies report readmission rates of decompensated cirrhosis at approximately $20 \%$ at 30 days and $30 \%$ at 90 days [1, 3-5, 13, 20-23]. In addition, patients with decompensated cirrhosis are often requiring more than one readmission within a 6-month period [2, 4].

There is insufficient evidence that a telemonitoring intervention would influence rates or timing of liver transplantation or death. Given this, we did not include liver transplantation or death in our model.

\section{Model Analysis}

We used Microsoft Excel to construct the model. We included a cost of $\$ 50,000$ for 6 months of the telemonitoring intervention to cover staffing and supplies. We then performed a sensitivity analysis adjusting parameter probabilities by $\pm 10 \%$ and costs by $\pm 20 \%$. We also performed sensitivity analyses varying the cost of and adherence to the telemonitoring intervention.

\section{Results}

The cost of standard of care for 100 patients with cirrhotic ascites over a 6-month period is $\$ 1,221,500$ based on the most likely event probabilities, an average bundled outpatient visit cost of \$202, outpatient LVP cost of \$1,619 each, and admission costs of $\$ 26,006$ (Table 4). The cost of care with a telemonitoring intervention was $\$ 167,500$ less expensive than standard of care, using the most likely probabilities of events, the same costs as standard of care for outpatient and inpatient encounters, and a \$50,000 cost for 6 months of the telemonitoring intervention. We then varied parameter probabilities by $\pm 10 \%$ and outcome costs by $\pm 20 \%$ and found that standard of care remained more expensive than care with a telemonitoring intervention by \$9400-\$340,200.

Standard of care led to 9 more admissions in a 6-month period than a telemonitoring intervention, while telemonitoring led to 9 more outpatient visits and 28 additional outpatient LVPs in the same period. We then varied parameter probabilities by $\pm 10 \%$ and standard of care still led to more hospital admissions (range 4 to 12 ), fewer outpatient visits (range 6 to 9), and fewer outpatient paracenteses (range 17 to 28$)$.

We then performed a sensitivity analysis varying the cost of the telemonitoring intervention. With a less expensive telemonitoring intervention (\$25,000/6-month period), standard of care was more expensive than telemonitoring by $\$ 192,500$ (range $\$ 34,400$ to $\$ 365,200$ ). With a more expensive telemonitoring intervention $(\$ 100,000 / 6-$ month period), standard of care was more expensive than telemonitoring by $\$ 117,500$, though with varying parameter probabilities by $\pm 10 \%$ and outcome costs by $\pm 20 \%$ the range included $-\$ 40,600$ to $\$ 290,200$.

We then performed a sensitivity analysis varying adherence to the intervention. With $50 \%$ adherence to the intervention, modeled using parameter probabilities halfway

Table 3 Cost parameters

\begin{tabular}{|c|c|c|c|c|}
\hline Cost parameter & Cost $(\$)$ & Source & $\operatorname{Low}(\$)^{\mathrm{a}}$ & $\operatorname{High}(\$)^{\mathrm{b}}$ \\
\hline \multicolumn{5}{|l|}{ Itemized costs } \\
\hline Hospitalization for cirrhosis complication & 25,633 & FY'18 DRG 432, 433, 434 & 20,506 & 30,759 \\
\hline Inpatient physician fee (initial) & 220 & Medicare fee schedule CPT 99,223 & - & - \\
\hline Inpatient physician fee (subsequent) & 113 & Medicare fee schedule CPT 99,233 & - & - \\
\hline Outpatient visit (subsequent) & 162 & Medicare fee schedule CPT 99,214, 99,215 & - & - \\
\hline Outpatient paracentesis (procedure code) & 347 & Medicare fee schedule CPT 49,083 & - & - \\
\hline Outpatient paracentesis (provider fee) & 1272 & Medicare fee schedule & - & - \\
\hline $\begin{array}{l}\text { Laboratory panel (basic metabolic panel, com- } \\
\text { plete blood count, liver biochemistries) }\end{array}$ & 40 & MGH standard charges & - & - \\
\hline \multicolumn{5}{|l|}{ Bundled costs ${ }^{\mathrm{b}}$} \\
\hline Outpatient visit & 202 & - & - & - \\
\hline Hospitalization & 26,006 & - & 20,804 & 31,207 \\
\hline LVP & 1619 & - & - & - \\
\hline
\end{tabular}

a "Low" sensitivity analysis is $20 \%$ lower than the predicted cost. "High" sensitivity analysis is $20 \%$ more expensive

${ }^{b}$ Outpatient visit included one set of labs and subsequent office visit fee. Hospitalization includes DRG cost, 2 initial consultations, and 2 subsequent visits per day for 7 days 
Table 4 Model outputs for 100 patients in 6 months

\begin{tabular}{|c|c|c|c|c|}
\hline Model & Cost $(\$)$ & Admissions (\#) & $\begin{array}{l}\text { Outpatient } \\
\text { visits (\#) }\end{array}$ & $\begin{array}{l}\text { Outpatient } \\
\text { paracenteses } \\
(\#)\end{array}$ \\
\hline Standard of care & $1,221,500$ & 37 & 112 & 105 \\
\hline Telemonitoring intervention ${ }^{\mathrm{a}}$ & $1,054,000$ & 28 & 121 & 133 \\
\hline Incremental change & $-167,500$ & -9 & +9 & +28 \\
\hline \multicolumn{5}{|l|}{ Sensitivity analyses } \\
\hline \multicolumn{5}{|l|}{ Low probability, low cost } \\
\hline Standard of care & 225,900 & 7 & 86 & 33 \\
\hline Telemonitoring intervention ${ }^{\mathrm{a}}$ & 216,500 & 3 & 95 & 50 \\
\hline Incremental change & -9400 & -4 & +9 & +17 \\
\hline \multicolumn{5}{|l|}{ Low probability, high cost } \\
\hline Standard of care & 303,800 & 7 & 86 & 33 \\
\hline Telemonitoring intervention ${ }^{a}$ & 250,500 & 3 & 95 & 50 \\
\hline Incremental change & $-53,300$ & -4 & +9 & +17 \\
\hline \multicolumn{5}{|l|}{ High probability, low cost } \\
\hline Standard of care & $2,088,000$ & 77 & 140 & 201 \\
\hline Telemonitoring intervention ${ }^{\mathrm{a}}$ & $1,891,100$ & 65 & 146 & 225 \\
\hline Incremental change & $-196,900$ & -12 & +6 & +24 \\
\hline \multicolumn{5}{|l|}{ High probability, high cost } \\
\hline Standard of care & $2,954,800$ & 77 & 140 & 201 \\
\hline Telemonitoring intervention ${ }^{a}$ & $2,614,600$ & 65 & 146 & 225 \\
\hline Incremental change & $-340,200$ & -12 & +6 & +24 \\
\hline
\end{tabular}

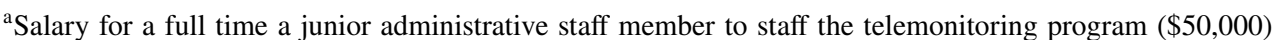
was added to the cost of the telemonitoring intervention in every analysis between those predicted for standard of care and telemonitoring intervention, we found that the standard of care was $\$ 89,848$ more expensive, led to 5 more admissions, 5 fewer outpatient visits, and 11 fewer LVPs.

\section{Discussion}

In this study, we evaluated the potential change in cost and outcomes with utilization of a telemonitoring system for ascites. Compared to current practice, a telemonitoring intervention could save a third-party payer $\$ 167,500$ over 6 months for every 100 patients and prevent 9 hospital admissions. Even in sensitivity analyses of different probability and cost scenarios, a telemonitoring intervention is likely to be cost-saving and leads to improved outcomes for patients with cirrhosis and ascites.

A telemonitoring intervention reduces inpatient care by expanding opportunities for outpatient care. The few published programs increasing outpatient care monitoring in cirrhosis patients have increased the volume of outpatient care $[6,7,9]$. In our model, a telemonitoring system could increase the number of outpatient visits by 9 per 100 patients (range: 6-9) and LVPs by 28 (range: 17-28) per 100 patients over 6 months. In order for a telemonitoring intervention to succeed, outpatient resources would need to be responsive to the alerts and have the capacity to accommodate this increase in utilization.

Cost savings are not the only potential benefits from a telemonitoring program for ascites. Prior studies have found that patients with cirrhotic ascites and a weight gain or loss of more than $5 \mathrm{lb}$ have a significantly higher rate of readmission [12]. Hospital admissions are associated with poor quality of life broadly as well as specifically in patients with cirrhosis [24]. Any intervention which could reduce hospital admissions would also likely increase quality of life.

Our model accounts for most of the cost of the telemonitoring intervention by including staff salary and smart scales. In our experience, a telemonitoring program can be managed by a junior administrative staff member or medical assistant. The other costs not included in our model are any additional staffing, if needed, to manage the additional outpatient care volume. Finally, programs could offer to provide home smart equipment such as phones or tablets to patients as part of the intervention. We performed a sensitivity analysis with a more expensive telemonitoring intervention costing \$100,000 every 6 months, and in most probability and cost scenarios, the telemonitoring intervention remained cost saving.

Healthcare delivery interventions, including telemedicine, do not have perfect adherence in the real world. Even 
in a sensitivity analysis with 50\% adherence, the telemonitoring intervention was cost saving and improved quality outcomes.

Our study used Medicare cost data to approximate the transactional costs from a societal perspective. Costs for each institution will vary and with each patient and payer. Hospitals or systems who receive less than their operational expenses may find the cost savings from a telemedicine intervention even more compelling. In addition, we used the cost of outpatient LVP performed by interventional radiology because that is the most common situation at our institution, though LVP cost may vary depending on location and staff performing this procedure.

Our model is focused on ascites and its potential complications. Competing events such as hepatic encephalopathy, liver transplantation, and death are not included. There is very limited data regarding how telemonitoring would influence those outcomes, and including them would increase uncertainty about model outputs. We also did not compare telemonitoring to other interventions such as increasing frequency of outpatient visits. This model also does not take into account patients with end-stage renal disease or congestive heart failure, in whom a weight monitoring program may not provide as much benefit. Finally, pilot data suggest that providers do not experience alert fatigue with 1-3 months of patient enrollment, but provider adherence may wane with longer enrollment [7]. As preliminary data become available in the future, these outcomes should be included.

In conclusion, care for patients with cirrhotic ascites was enhanced by telemedicine and was less expensive for each scenario analyzed. Using hospital admissions as a surrogate for quality of care, patient outcomes were improved primarily though more proactive medical intervention and more LVPs. Telemedicine is emerging as a critical part of ambulatory care in the present COVID-19 era providing access to timely and safe care this analysis suggests that it is cost effective too.

Supplementary Information The online version contains supplementary material available at https://doi.org/10.1007/s10620-021-07013-2.

\section{Declarations}

Conflict of interest Dr. Bloom receives funding from the AASLD Advanced Transplant Hepatology Award and ACG Junior Faculty Award and has consulted for Synlogic Inc. Dr. Tapper receives funding from the National Institutes of Health (K23DK117055, KL2TR002241). The content is solely the responsibility of the authors and does not necessarily represent the official views of the National Institutes of Health. Dr. Tapper serves on advisory boards for Bausch Health, Rebiotix, and Mallinckrodt, consulted for Axcella, Kaleido, and Novo Nordisk. No other author has relevant conflict of interest.

\section{References}

1. Tapper EB, Halbert B, Mellinger J. Rates of and reasons for hospital readmissions in patients with cirrhosis: a multistate populationbased cohort study. Clin Gastroenterol Hepatol. 2016;14:1181-8. e2.

2. Bajaj JS, Reddy KR, Tandon P, Wong F, Kamath PS, Garcia-Tsao $\mathrm{G}$ et al. The 3-month readmission rate remains unacceptably high in a large North American cohort of patients with cirrhosis. Hepatology. 2016;64:200-208.

3. Shaheen AA, Nguyen HH, Congly SE, Kaplan GG, Swain MG. Nationwide estimates and risk factors of hospital readmission in patients with cirrhosis in the United States. Liver Int. 2019;39:878-884.

4. Volk ML, Tocco RS, Bazick J, Rakoski MO, Lok AS. Hospital readmissions among patients with decompensated cirrhosis. Am J Gastroenterol. 2012;107:247-252.

5. Morales BP, Planas R, Bartoli R, Morillas RM, Sala M, Casas I et al. HEPACONTROL. A program that reduces early readmissions, mortality at 60 days, and healthcare costs in decompensated cirrhosis. Dig Liver Dis. 2018;50:76-83.

6. Wigg AJ, McCormick R, Wundke R, Woodman RJ. Efficacy of a chronic disease management model for patients with chronic liver failure. Clin Gastroenterol Hepatol. 2013;11:850-858.

7. Bloom P, Wang T, Marx M, Tagerman M, Green B, Arvind A et al. A smartphone app to manage cirrhotic ascites among outpatients: feasibility study. JMIR Med Inform. 2020;8:e17770.

8. Siddique SM, Porges S, Lane-Fall M, Mehta SJ, Schweickert W, Kinniry J et al. Reducing hospital admissions for paracentesis: a quality improvement intervention. Clin Gastroenterol Hepatol. 2019;17:2630-3.e2.

9. Morando F, Maresio G, Piano S, Fasolato S, Cavallin M, Romano A et al. How to improve care in outpatients with cirrhosis and ascites: a new model of care coordination by consultant hepatologists. J Hepatol. 2013;59:257-264.

10. Runyon BA. Introduction to the revised American Association for the Study of Liver Diseases Practice Guideline management of adult patients with ascites due to cirrhosis 2012. Hepatology. 2013;57:1651-1653.

11. Pericleous M, Sarnowski A, Moore A, Fijten R, Zaman M. The clinical management of abdominal ascites, spontaneous bacterial peritonitis and hepatorenal syndrome: a review of current guidelines and recommendations. Eur J Gastroenterol Hepatol. 2016;28:e10-e18.

12. Thomson M, Volk M, Kim HM, Piette JD. An automated telephone monitoring system to identify patients with cirrhosis at risk of re-hospitalization. Dig Dis Sci. 2015;60:3563-3569. https://doi. org/10.1007/s10620-015-3744-3.

13. Seraj SM, Campbell EJ, Argyropoulos SK, Wegermann K, Chung RT, Richter JM. Hospital readmissions in decompensated cirrhotics: factors pointing toward a prevention strategy. World J Gastroenterol. 2017;23:6868-6876.

14. Moore KP, Wong F, Gines P, Bernardi M, Ochs A, Salerno F et al. The management of ascites in cirrhosis: report on the consensus conference of the International Ascites Club. Hepatology. 2003;38:258-266.

15. Planas R, Montoliu S, Ballesté B, Rivera M, Miquel M, Masnou $\mathrm{H}$ et al. Natural history of patients hospitalized for management of cirrhotic ascites. Clin Gastroenterol Hepatol. 2006;4:1385-1394.

16. Montoliu S, Ballesté B, Planas R, Alvarez MA, Rivera M, Miquel $\mathrm{M}$ et al. Incidence and prognosis of different types of functional renal failure in cirrhotic patients with ascites. Clin Gastroenterol Hepatol. 2010;8:616-622.

17. Angeli P, Fasolato S, Mazza E, Okolicsanyi L, Maresio G, Velo $\mathrm{E}$ et al. Combined versus sequential diuretic treatment of ascites 
in non-azotaemic patients with cirrhosis: results of an open randomised clinical trial. Gut. 2010;59:98-104.

18. Pache I, Bilodeau M. Severe haemorrhage following abdominal paracentesis for ascites in patients with liver disease. Aliment Pharmacol Ther. 2005;21:525-529.

19. Adebayo D, Neong SF, Wong F. Ascites and hepatorenal syndrome. Clin Liver Dis. 2019;23:659-682.

20. Le S, Spelman T, Chong CP, Ha P, Sahhar L, Lim J et al. Could adherence to quality of care indicators for hospitalized patients with cirrhosis-related ascites improve clinical outcomes? Am J Gastroenterol. 2016;111:87-92.

21. Peery AF, Crockett SD, Barritt AS, Dellon ES, Eluri S, Gangarosa LM et al. Burden of gastrointestinal, liver, and pancreatic diseases in the United States. Gastroenterology. 2015;149:1731-41.e3.

22. Scaglione SJ, Metcalfe L, Kliethermes S, Vasilyev I, Tsang R, Caines A et al. Early hospital readmissions and mortality in patients with decompensated cirrhosis enrolled in a large national health insurance administrative database. J Clin Gastroenterol. 2017;51:839-844.

23. Gaspar R, Rodrigues S, Silva M, Costa-Moreira P, Morais R, Andrade $\mathrm{P}$ et al. Predictive models of mortality and hospital readmission of patients with decompensated liver cirrhosis. Dig Liver Dis. 2019;51:1423-1429.

24. Kok B, Whitlock R, Ferguson T, Bailey RJ, Burak KW, Kowalczewski $\mathrm{J}$ et al. Health-related quality of life: a rapid predictor of hospitalization in patients with cirrhosis. Am J Gastroenterol. 2020;115:575-583.

Publisher's Note Springer Nature remains neutral with regard to jurisdictional claims in published maps and institutional affiliations. 